\title{
Motor function predicts parent-reported musculoskeletal pain in children with cerebral palsy
}

\author{
Chantel C Barney $M A^{1,2}$, Linda E Krach $\mathrm{MD}^{2,3}$, Patrick F Rivard RN², John L Belew PhD², Frank J Symons PhD ${ }^{1}$
}

\begin{abstract}
CC Barney, LE Krach, PF Rivard, JL Belew, FJ Symons. Motor function predicts parent-reported musculoskeletal pain in children with cerebral palsy. Pain Res Manag 2013;18(6):323-327.
\end{abstract}

BACKGROUND: The relationship between pain and motor function is not well understood, especially for children and adolescents with communication and motor impairments associated with cerebral palsy (CP).

OBJECTIVES: To determine whether a predictive relationship between motor function and musculoskeletal pain exists in children with CP.

METHODS: Following informed consent, caregivers of 34 pediatric patients with CP (mean $[ \pm \mathrm{SD}$ ] age $9.37 \pm 4.49$ years; $80.0 \%$ male) completed pain- and function-related measures. Parents completed the Dalhousie Pain Interview and the Brief Pain Inventory based on a oneweek recall to determine whether pain had been experienced in the past week, its general description, possible cause, duration, frequency, intensity and interference with daily function. The Gross Motor Function Classification System (GMFCS) was used to classify the motor involvement of the child based on their functional ability and their need for assistive devices for mobility.

RESULTS: GMFCS level significantly predicted parent-reported musculoskeletal pain frequency $(\mathrm{P}<0.02)$, duration $(\mathrm{P}=0.05)$ and intensity $(\mathrm{P}<0.01)$. Duration of pain was significantly related to interference with activities of daily living $(\mathrm{P}<0.05)$.

CONCLUSIONS: Children with CP with greater motor involvement, as indexed by GMFCS level, may be at risk for increased pain (intensity, frequency and duration) that interfers with activities of daily living. The clinical index of suspicion should be raised accordingly when evaluating children with developmental disability who cannot self-report reliably.

Key Words: Cerebral palsy; Developmental disability; GMFCS; Motor function; Pain

$\mathrm{C}$ erebral palsy (CP) is the most common congenital cause of disability in children, affecting approximately two to three per 1000 live births (1). Spasticity is reported in approximately $70 \%$ of children with $\mathrm{CP}$ and, depending on severity, results in chronic pain and interferes with function and comfort. For children and adolescents with communication and motor impairments associated with $\mathrm{CP}$, the relationship between pain and motor function is not completely understood, partly because it is difficult to ascertain pain levels using conventional methods (ie, self-report).

Musculoskeletal-related health and pain problems are of concern in CP, particularly given the fact that the treatment of CP is focused extensively on musculoskeletal-related issues (eg, physical therapy, orthopedic surgery, etc - all designed to improve movement and motor-related outcomes). There is little doubt that chronic abnormal muscle tone is related to pain. It has been shown that abnormal muscle tone is influenced by abnormal posture, and that hypertonia interferes with normal movement and is associated with pain and contracture (2). Despite this, there has been relatively little work explicitly investigating the relationship between motor function and musculoskeletal pain in children with CP.

\section{La motricité indicatrice des douleurs musculosquettiques déclarées par les parents chez les enfants ayant une paralysie cérébrale}

HISTORIQUE : On comprend mal le lien entre la douleur et la motricité, particulièrement chez les enfants et les adolescents ayant des problèmes de communication et des troubles moteurs liés à la paralysie cérébrale (PC). OBJECTIFS : Déterminer s'il y a un lien indicateur entre la motricité et la douleur musculosquelettique chez les enfants ayant la PC.

MÉTHODOLOGIE : Après avoir donné leur consentement éclairé, les personnes qui s'occupaient de 34 patients d'âge pédiatrique ayant la

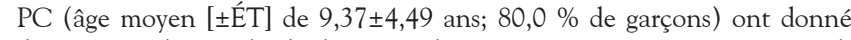
des mesures liées à la douleur et à la motricité. Les parents ont rempli l'entrevue de Dalhousie sur la douleur et l'inventaire bref de la douleur selon ce dont ils se souvenaient depuis une semaine afin de déterminer s'il y avait eu de la douleur pendant la semaine précédente, sa description générale, sa cause possible, sa durée, sa fréquence, son intensité et l'interférence avec la fonction quotidienne. Les chercheurs ont utilisé le système de classification de la motricité globale (SCMG) pour déterminer la part de la motricité de l'enfant d'après la capacité fonctionnelle et le besoin de dispositifs d'aide à la mobilité.

RÉSULTATS : Le taux du SCMG était un indicateur significatif de la fréquence $(\mathrm{P}<0,02)$, de la durée $(\mathrm{P}=0,05)$ et de l'intensité $(\mathrm{P}<0,01)$ de la douleur musculosquelettique. La durée de la douleur s'associait de manière significative à l'interférence avec les activités de la vie quotidienne $(\mathrm{P}<0,05)$.

CONCLUSIONS : Les enfants ayant la PC et une atteinte motrice plus importante selon le SCMG peuvent être à risque d'une plus grande douleur (sur le plan de l'intensité, de la fréquence et de la durée), qui nuit aux activités de la vie quotidienne. Il faut accroître l'indice clinique de présomption en conséquence lorsqu'on évalue des enfants ayant des troubles du développement qui ne peuvent pas répondre eux-mêmes de manière fiable.

In an extensive study exploring musculoskeletal pain in $\mathrm{CP}$, Ramstad et al (3) found that this type of pain was experienced by $62 \%$ of the study group across a full range of motor ability, as measured by the Gross Motor Function Classification System (GMFCS). Although the descriptive data suggested that pain prevalence was greater among the more severely motor impaired (approximately $83 \%$ of children rated GMFCS IV or V were reported to have recurrent musculoskeletal pain), there did not appear to be a predictive relationship between the gross motor ratings and pain level. On the other hand, Bartlett et al (1) found that recurring pain was predictive of decline in gross motor function capability in adolescents with CP. Houlihan et al (4), in a sample of children with GMFCS levels of III to V, reported that the frequency of pain experienced was significantly related to severity of motor impairment and the presence of a gastrostomy tube $(\mathrm{P}<0.05)$. In a subsequent study, Houlihan et al (5) reported that children who were classified by their parents as GMFCS IV exhibited increased pain intensity, as scored on the Varni-Thompson Pediatric Pain Questionnaire, compared with children in the same sample who were classified as GMFCS I; however, this relationship was not explored statistically. Breau et al (6) investigated the relationship between

${ }^{1}$ Department of Educational Psychology, University of Minnesota; ${ }^{2}$ Gillette Children's Specialty Healthcare; ${ }^{3}$ Department of Physical and Medical Rehabilitation, University of Minnesota, Minneapolis, Minnesota, USA

Correspondence: Ms Chantel C Barney, 250 Education Sciences Building, 56 East River Road, Minneapolis, Minnesota 55455, USA.

Telephone 651-724-8212, fax 612-624-8241, e-mail burki005@umn.edu 


\begin{tabular}{|c|c|}
\hline \multicolumn{2}{|l|}{ Characteristic } \\
\hline \multicolumn{2}{|l|}{ Sex } \\
\hline Male & $27(79.4)$ \\
\hline Female & $7(20.6)$ \\
\hline \multicolumn{2}{|l|}{ Age, years } \\
\hline Mean \pm SD & $8.95 \pm 3.81$ \\
\hline Range & 4 to 18 \\
\hline \multicolumn{2}{|l|}{ Race/ethnicity } \\
\hline Caucasian & $30(88.2)$ \\
\hline African-American & $1(2.9)$ \\
\hline Asian & $0(0)$ \\
\hline Hispanic & $0(0)$ \\
\hline Other & $3(8.8)$ \\
\hline \multicolumn{2}{|l|}{ Type of cerebral palsy } \\
\hline Quadriplegia & $23(67.6)$ \\
\hline Triplegia & $2(5.9)$ \\
\hline Diplegia & $9(26.5)$ \\
\hline \multicolumn{2}{|l|}{ Gross Motor Function Classification System level } \\
\hline I (ambulant without assistance) & $5(14.7)$ \\
\hline $\begin{array}{l}\text { II (ambulant without assistive devices, limitations outside } \\
\text { home) }\end{array}$ & $2(5.9)$ \\
\hline $\begin{array}{l}\text { III (ambulant with assistive devices, wheelchair required } \\
\text { outside home) }\end{array}$ & $9(26.5)$ \\
\hline $\begin{array}{l}\text { IV (nonambulatory, self-mobile in wheelchair with } \\
\text { limitations) }\end{array}$ & $8(23.5)$ \\
\hline V (nonambulatory, self-mobility very limited) & $10(29.4)$ \\
\hline \multicolumn{2}{|l|}{ Gestational age at birth } \\
\hline Term (37 to 40 weeks) & $5(14.7)$ \\
\hline Preterm (32 to 35 weeks) & $3(8.8)$ \\
\hline Very preterm ( 28 to 30 weeks) & $12(35.3)$ \\
\hline Extremely preterm ( 23 to 27 weeks) & $14(41.2)$ \\
\hline \multicolumn{2}{|l|}{ Pain in seven days before study } \\
\hline Yes & $32(94.1)$ \\
\hline No & $2(5.8)$ \\
\hline
\end{tabular}

Data presented as $n(\%)$ unless otherwise specified

global functional ability and pain among children with developmental disabilities, including CP, and showed that pain impacted all areas of functional ability, including motor skills. Children with the fewest functional abilities in every subdomain experienced the most nonaccidental pain; conversely, children with the most motor skills experienced the most accidental pain. Overall, those with the fewest functional abilities had the most pain. In a later study conducted by Breau et al (7), the researchers demonstrated that children with intellectual disabilities performed fewer pre-existing skills on days when pain was present compared with pain-free days. Pain impacted communication, daily living skills, and social and motor skills for all children, but functioning in these areas was most impacted for children who had the most severe intellectual disabilities.

In the study by Ramstad et al (3), severely motor-impaired children made up only a small proportion of the total sample, which reduced the statistical power to detect a relationship between severity of motor impairment and pain. The first study by Houlihan et al (4) did not include children with GMFCS I or II, and the second study by Houlihan et al (5) did not conduct statistical analyses to determine significance. The samples used by Breau et al $(6,7)$ were not specific to $\mathrm{CP}$, and the Houlihan et al $(4,5)$ and Breau et al $(6,7)$ studies were not specific to musculoskeletal pain. In the present investigation, our overall goal was to continue to improve our understanding of musculoskeletal pain in pediatric populations with CP by specifically testing whether motor function measured by the GMFCS predicted spasticityrelated pain. The aim, in part, was to replicate previous work and extend it by including children with $\mathrm{CP}$ with a range of motor impairments (GMFCS I through V) in the sample.

\section{METHODS}

The present study was conducted at a specialty children's rehabilitation hospital following review and approval by the committee for the protection of human subjects (ie, the institutional review board) through the University of Minnesota (Minneapolis, Minnesota, USA). Informed consent was obtained from the primary caregiver of each child who participated. A convenience sample consisting of 34 consecutively enrolled pediatric patients $(27$ male) participated in the study (Table 1).

At the time of a hospital visit before an indicated surgical procedure (intrathecal baclofen pump implant, selective dorsal rhizotomy, etc), the child's primary caregivers completed the Dalhousie Pain Interview (DPI [6]) and the Brief Pain Inventory (BPI [8]). The DPI is presented in an interview/script format consisting of 10 closed-ended questions that provide a measure of pain. This measure has been adapted from the methodology used in previous research for obtaining pain information via proxy report when self-report is not possible or otherwise difficult to obtain (6). Specific items are anchored to whether there has been pain in the past week, its general description, possible cause, duration (cumulative hours, minutes, and seconds), frequency (number of episodes) and intensity (0 to 10; 0 means "no pain at all" and 10 means the "worst pain ever"). All pain episodes reported are categorized as accidental, gastrointestinal, musculoskeletal, neurological, stretching, positioning, equipment, orthopedic, spasm, other or unknown. For the purposes of investigating musculoskeletal-related pain, musculoskeletal, stretching, equipment, positioning, orthopedic, and spasm pain types were grouped together for analyses (hereafter, this grouping of pain types is referred to as 'musculoskeletal pain'). This grouping was used because musculoskeletal pain is considered to originate from the muscles, bones or joints; therefore, that would include pain during stretching, pain related to using equipment (eg, stander, braces, etc), discomfort from sitting too long or poor positioning, and pain from muscle spasms. Pain episodes related to accidents, injuries, gastrointestinal issues, seizures and headaches were not included in the main analyses.

The BPI was developed initially as a method of measuring cancer pain (8); however, the tool has since been revised and validated for use with individuals with CP (9). The BPI was designed to efficiently measure the extent to which pain interfered with 12 different aspects of daily living, such as communication, mobility, school, daily activities, self-care, sleep and mood in the previous week. Each of the 12 items are scored from 0 to 10 , with 0 meaning pain "did not interfere" with that item and 10 meaning pain "completely interfered" with that item. Each item score is the 0 to 10 score assigned by the rater. There are no subscale scores. Each participant receives a total score based on the sum of the 0 to 10 scores for each of 12 items. Thus, individual total scores have the potential to range from 0 to 120. Pain interference scores on the BPI have shown significant correlations with pain intensity ratings and excellent internal consistency $(9,10)$.

Motor capacity was evaluated by the GMFCS, which was obtained from medical record chart review. GMFCS levels were assigned by experienced orthopedic physicians at the specialty children's rehabilitation hospital who are very familiar with the GMFCS, as well as children and adolescents with CP. The GMFCS provides a measure of motor involvement based on self-initiated movement, with specific attention given to truncal control and walking (11). The GMFCS is a five-level classification system, with level I indicating the least motor involvement and level $\mathrm{V}$ indicating the most motor involvement. A person classified as GMFCS I is able to walk with virtually no limitations. A person classified as GMFCS II is able to walk with limitations, is less able to run and jump, and may need assistance when travelling 
TABLE 2

Most common pain types and intensity (scored 0 to 10) reported according to Gross Motor Function Classification System level (9) for all types of pain

\begin{tabular}{|c|c|c|c|}
\hline \multirow[b]{2}{*}{ Gross Motor Function Classification System level } & \multicolumn{3}{|c|}{ Pain source* } \\
\hline & Most common & Second most common & Third most common \\
\hline I (ambulant without assistance; $n=5)$ & Stretching $(3.0 \pm 0.0 ; 3-3)$ & Accidental $(1.5 \pm 0.71 ; 1-2)$ & \\
\hline II (ambulant without assistive devices, limitations outside home; n=2) & Stretching $(5.5 \pm 3.54 ; 3-8)$ & & \\
\hline III (ambulant with assistive devices, wheelchair required outside home; $n=9$ ) & Stretching $(3.0 \pm 1.63 ; 1-5)$ & Accidental $(6.0 \pm 0.0 ; 6-6)$ & \\
\hline IV (nonambulatory, self-mobile in wheelchair with limitations; $n=8$ ) & Stretching $(6.2 \pm 2.77 ; 3-10)$ & Accidental $(6.0 \pm 2.83 ; 4-8)$ & Positioning $(4.0 \pm 1.41 ; 3-5)$ \\
\hline V (nonambulatory, self-mobility very limited; $n=10$ ) & Stretching $(4.17 \pm 0.98 ; 3-5)$ & $\begin{array}{l}\text { Musculoskeletal } \\
(4.67 \pm 0.58 ; 4-5)\end{array}$ & $\begin{array}{l}\text { Gastrointestinal } \\
(4.67 \pm 3.79 ; 2-9)\end{array}$ \\
\hline
\end{tabular}

Data presented as mean $\pm S D$; range. *Pain source is not listed if only one participant reported experiencing that type of pain

TABLE 3

Intensity, duration and frequency of musculoskeletal pain experienced in the previous seven-day period according to Gross Motor Function Classification System level

\begin{tabular}{|c|c|c|c|}
\hline Gross Motor Function Classification System level & $\begin{array}{l}\text { Pain intensity } \\
\text { (scored 0-10) }\end{array}$ & Pain duration, $\mathbf{s}$ & $\begin{array}{l}\text { Pain frequency } \\
\text { (episodes, n) }\end{array}$ \\
\hline I (ambulant without assistance; n=5) & $1.20 \pm 1.64 ; 0-3$ & $16.20 \pm 26.12 ; 0-60$ & $2.00 \pm 3.08 ; 0-7$ \\
\hline II (ambulant without assistive devices, limitations outside home; n=2) & $5.50 \pm 3.53 ; 3-8$ & $24.00 \pm 12.73 ; 15-33$ & $4.00 \pm 0.00 ; 4-4$ \\
\hline III (ambulant with assistive devices, wheelchair required outside home; $n=9$ ) & $1.44 \pm 1.81 ; 0-5$ & $155.67 \pm 281.83 ; 0-780$ & $2.56 \pm 3.40 ; 0-10$ \\
\hline IV (nonambulatory, self-mobile in wheelchair with limitations; $n=8$ ) & $4.88 \pm 3.48 ; 0-10$ & $99.75 \pm 150.55 ; 0-420$ & $5.25 \pm 5.09 ; 0-14$ \\
\hline V (nonambulatory, self-mobility very limited; $n=10)^{*}$ & $4.90 \pm 1.29 ; 3-8$ & $516.22 \pm 741.63 ; 7-1800$ & $16.90 \pm 20.70 ; 4-70$ \\
\hline
\end{tabular}

Data reported as mean $\pm S D$; range. *Pain duration missing for one participant classified as GMFCS level V

long distances or on stairs. A person classified as GMFCS III can sit on their own and stand during transfers, but requires a hand-held mobility device to be self-mobile and may require wheeled mobility outdoors and in the community. A person classified as GMFCS IV can sit when supported and can be self-mobile with a powered wheelchair. A person classified as GMFCS V has severe limitations in head and trunk control and requires extensive assistance to be mobile (11). The distinction among levels is based on functional limitations, the need for assistive devices for mobility and the quality of movement. The GMFCS has shown strong reliability and content validity in previous studies (12), and is used clinically and in classifying individuals with CP for research.

Analyses were performed using SPSS version 19.0 (IBM Corporation, USA) with alpha (type I error) set at 0.05. Descriptive statistics were generated for demographic factors and pain information (ie, pain type, duration, intensity, number of episodes and interference). Descriptive data were summarized using means, proportions and ranges. Total pain duration was not completed by one participant; therefore, that participant was excluded from analyses specific to pain duration. To test GMFCS level as a potential predictor of musculoskeletal pain intensity (scored 0 to 10 as reported), duration (total based on cumulative hours, minutes and seconds of reported pain) and frequency (number of episodes reported), simple linear regression models were developed and fitted separately. Differences in musculoskeletal pain intensity, frequency and duration across GMFCS levels were analyzed using one-way ANOVA, and Tukey's post hoc tests for multiple comparisons were performed when necessary.

\section{RESULTS}

Primary caregivers (parents) reported on the specific subtypes of musculoskeletal pain their child experienced; 18 (53\%) reported pain during stretching, five (15\%) reported general musculoskeletal pain, three $(9 \%)$ reported pain related to positioning, two $(6 \%)$ reported pain related to equipment (eg, ankle-foot orthotic use), one (3\%) reported orthopedic pain and one $(3 \%)$ reported pain from spasms. Nonmusculoskeletal pain included the following: six participants reported gastrointestinal pain; six reported pain related to accidents or injury; six reported headaches; and two reported other or unknown pain. Parents were asked to recall pain frequency (number of episodes), duration (cumulative hours, minutes and seconds) and intensity (scored 0 to 10) of pain episodes that had occurred in the previous seven days. A total of 252 episodes of musculoskeletal types of pain were reported for the previous week (mean $[ \pm$ SD] $6.81 \pm 12.51$ episodes). The mean duration of all types of musculoskeletal pain episodes was $3 \mathrm{~min} 42 \mathrm{~s} \pm 7 \mathrm{~min} 38 \mathrm{~s}$ (range $0 \mathrm{~min}$ to $30 \mathrm{~min}$ ) and the mean intensity of all types of musculoskeletal pain episodes on an 11 -point scale was $3.37 \pm 2.81$ (range 0 to 10 ). Of every specific type of pain reported (including nonmusculoskeletal pain), stretching pain was reported to be the most intense $(2.30 \pm 2.75$ on a scale from 0 to $10)$ and the most frequent $(3.57 \pm 4.48$ episodes $)$ pain experienced. Gastrointestinal pain was, on average, the longest in duration $(2.34 \pm 9.30 \mathrm{~h})$. The most common types of pain experienced by individuals classified within each GMFCS level are displayed in Table 2. Based on the item total scores on the BPI, pain most frequently interfered with mood (mean score $2.18 \pm 2.79$, proportion 0.17 ), sleep (mean score 2.00 \pm 3.57 , proportion 0.15 ), school (mean score $1.35 \pm 2.73$, proportion 0.10 ) and mobility (mean score $1.29 \pm 2.92$, proportion 0.10 ).

Spasticity pain duration $\left(\mathrm{r}^{2}=0.15\right.$ [adjusted $\mathrm{r}^{2}=0.12 ; \beta=109.91$, $t(30)=2.38 ; \mathrm{P}=0.02])$, but not pain frequency $(\beta=0.05, t[31]=0.44$; $\mathrm{P}=0.66)$, or intensity $(\beta=0.04, t[31]=1.67 ; \mathrm{P}=0.11)$ significantly predicted total score on the BPI $(13.09 \pm 21.22$, range 0 to 82$)$, which was used to characterize the extent to which pain interfered with daily functioning. GMFCS level significantly predicted musculoskeletal pain frequency $\left(r^{2}=0.16\right.$ [adjusted $r^{2}=0.13 ; \beta=4.14, t(31)=2.57$; $\mathrm{P}<0.02$ ]), duration $\left(\mathrm{r}^{2}=0.15\right.$ [adjusted $\mathrm{r}^{2}=0.12 ; \beta=119.36, t(30)=2.03$; $\mathrm{P}=0.05$ ] $)$ and intensity $\left(\mathrm{r}^{2}=0.21\right.$ [adjusted $\mathrm{r}^{2}=0.19 ; \beta=1.02, t(31)=3.03$; $\mathrm{P}<0.01]$ ) (Table 3 ). There was a significant main effect of GMFCS level on musculoskeletal pain intensity $(F[4,29]=5.35 ; \mathrm{P}=0.02)$, but not on musculoskeletal pain duration $(F[4,27]=1.54 ; \mathrm{P}=0.22)$ or frequency $(F[4,28]=2.29 ; \mathrm{P}=0.09)$. There was a significant difference between mean musculoskeletal pain intensity scores for GMFCS I $(1.2 \pm 1.64)$, and GMFCS IV $(4.88 \pm 3.48 ; \mathrm{P}=0.05)$ and GMFCS V $(4.90 \pm 1.29 ; \mathrm{P}=0.03)$. There was a significant difference between mean musculoskeletal pain scores for GMFCS III $(1.44 \pm 1.81)$, and GMFCS IV $(\mathrm{P}=0.03)$ and GMFCS V $(\mathrm{P}=0.02)$. The mean musculoskeletal pain score for GMFCS II $(5.50 \pm 3.54)$ did not differ significantly from the other levels. 


\section{DISCUSSION}

In a pediatric sample of individuals with $\mathrm{CP}$, we collected parent report of all types of pain, which were broadly categorized as either musculoskeletal or nonmusculoskeletal. The types of pain that were categorized as musculoskeletal included musculoskeletal, stretching, equipment, positioning, orthopedic and spasm. Stretching pain was especially problematic and was the most frequent and intense type of pain reported by parents. Similar findings were reported in another study, in which parents of children with CP reported that stretching pain was the most frequent and most intense daily living pain (13).

Pain of all types interfered with many aspects of daily living, especially with mood, sleep, school and mobility. We tested the relationship between motor function and musculoskeletal pain. The specific results indicated that motor function (GMFCS level) significantly predicted musculoskeletal pain frequency $(\mathrm{P}<0.02)$, duration $(\mathrm{P}=0.05)$ and intensity $(\mathrm{P}<0.01)$. We found, as did others (3-7), that there was a relationship between pain and motor function. Specifically, we found a significant difference in musculoskeletal pain intensity between ambulatory children with $\mathrm{CP}$ (GMFCS I and III) and nonambulatory children with CP (GMFCS IV and V). Also of interest, total scores on the BPI, a measure of pain interference, significantly predicted musculoskeletal pain duration $(\mathrm{P}=0.02)$. This appears to be intuitive given that pain of greater duration (perhaps independent of intensity) would have a cumulative effect and interfere more with activities of daily living and the child's ability to function than perhaps pain of shorter duration (even if more intense), although this is speculative and there would certainly be circumstances in which such a relationship would not hold. For example, Breau et al (7) found that pain intensity, but not duration, had an impact on children's functioning. This difference in findings may have been because the sample in the Breau et al (7) study was not specific to CP, the pain reported did not include musculoskeletal pain, and/or a different method was used to quantify pain's impact on function (Vineland Adaptive Behavior Scale).

More generally, we found that children with CP who had the most motor involvement also experienced the most intense, frequent and long-lasting musculoskeletal pain. This finding is especially troubling considering the gaps in research, which often excludes participants with the most limiting disabilities. Careful attention should be devoted to assessing pain and discomfort among individuals with the most severe motor involvement because pain may be present yet difficult to document through conventional approaches (ie, self-report) because of associated communicative impairments further exacerbating the difficulty of assessing a subjective emotional state $(14,15)$. Pain assessment scales have been developed specifically for individuals with intellectual, motor and communicative impairments, and are recommended for use by parents, caregivers and health care professionals to determine when there is a need for pain-relieving treatment (16-18).

There are some study-specific limitations that should be noted. Similar to almost all pain investigations among nonverbal or

\section{REFERENCES}

1. Bartlett DJ, Hanna SE, Avery L, Stevenson RD, Galuppi B. Correlates of decline in gross motor capacity in adolescents with cerebral palsy in Gross Motor Function Classification levels III to V: An exploratory study. Dev Med Child Neurol 2010;52:e155-e160.

2. Peacock WJ. The pathophysiology of spasticity. In: Gage JR, ed. The Treatment of Gait Problems in Cerebral Palsy. London: MacKeith Press, 2004:32-41.

3. Ramstad K, Jahnsen R, Skjeldal OH, Diseth TH. Characteristics of recurrent musculoskeletal pain in children with cerebral palsy aged 8 to 18 years. Dev Med Child Neurol 2011;53:1013-8.

4. Houlihan CM, O'Donnell M, Conaway M, Stevenson RD. Bodily pain and health-related quality of life in children with cerebral palsy. Dev Med Child Neurol 2004;46:305-10.

5. Houlihan CM, Hanson A, Quinlan N, Puryear C, Stevenson RD. Intensity, perception, and descriptive characteristics of chronic pain in children with cerebral palsy. J Pediatr Rehabil Med 2008;1:145-53.

6. Breau LM, Camfield CS, McGrath PJ, Finley GA. The incidence of pain in children with severe cognitive impairments. Arch Pediatr Adolesc Med 2003;157:1219-26. communicatively impaired clinical populations, the pain parameters reported were determined by parental proxy-report. In studies involving young children and those with communication impairments, such limitations of research design are unavoidable but should not preclude including them as participants in pain research. The sample was based on consecutive clinical enrollment and not on randomly sampling the population of pediatric $\mathrm{CP}$; thus, the inferences are specific to the study sample and are not necessarily representative of all children with CP. Finally, there may have been an ascertainment bias operating. The present study involved a group of children already scheduled for procedures designed to specifically address spasticity associated with CP. Our sample, therefore, may be more representative of children for whom their impairment or pain is such that surgical treatment is warranted.

There is still relatively little research focused on musculoskeletalspecific pain in children with CP, which is surprising considering that secondary musculoskeletal problems and disturbances in sensation and perception are now considered to be part of the CP diagnosis (19), and multiple medical procedures related to musculoskeletal management (ie, botulinum toxin injections, orthopedic surgery, etc [3]) are widespread. Given this, there is reason to further explore the characteristics and predictors of musculoskeletal pain in this population. In the present study, we did find a predictive relationship between GMFCS level and musculoskeletal pain, whereas Ramstad et al (3) did not. Possible reasons for this, as noted earlier, include difference in sample size representing more severely motor-impaired children (in our sample, we had a much greater proportion of GMFCS IV and V cases). Pain was also measured differently. We relied on a one-week recall window whereas Ramstad et al (3) based their estimates of severity (maximum intensity) on the previous one month for recurrent pain.

\section{Implications}

As noted by the results presented in the present article and those of Ramstad et al (3), musculoskeletal pain is prevalent and problematic in children with CP. We found that musculoskeletal pain could be predicted based on motor function (specifically, GMFCS level) such that those with greater motor involvement can be suspected to experience greater pain. This is an important area for future research exploration, and attention should be devoted to making improvements in clinical practice of assessing pain among children with severe motor impairments associated with CP.

DISCLOSURES: This work originated at the University of Minnesota and was conducted at Gillette Children's Specialty Healthcare. This research was supported, in part, by Gillette Children's Specialty Healthcare Research Administration with special thanks to Jody Evenson, the University of Minnesota's Futures Program, and NIH Grant No. 44763 \& 47201.

7. Breau LM, Camfield CS, McGrath PJ, Finley GA. Pain's impact on adaptive functioning. J Intellectual Disabil Res 2007;51:125-34.

8. Cleeland CS, Ryan KM. Pain assessment: Global use of the brief pain inventory. Ann Acad Med Singap 1994;23:129-38.

9. Tyler EJ, Jensen MP, Engel JM, Schwartz L. The reliability and validity of pain interference measures in persons with cerebral palsy. Arch Phys Med Rehabil 2002;83:236-9.

10. Osborne TL, Raichle KA, Jensen MP, Ehde DM, Kraft G. The reliability and validity of pain interference measures in persons with multiple sclerosis. J Pain Symptom Manage 2006;32:217-29.

11. Palisano RJ, Rosenbaum PL, Walter S, Russell D, Wood E, Galuppi B. Development and reliability of a system to classify gross motor function in children with cerebral palsy. Dev Med Child Neurol 1997;39:214-33.

12. Bodkin AW, Robinson C, Perales FP. Reliability and validity of the gross motor function classification system for cerebral palsy. Pediatr Phys Ther 2003;15:247-52.

13. Hadden KL, von Baeyer CL. Pain in children with cerebral palsy: Common triggers and expressive behaviors. Pain 2002;99:281-8. 
14. Breau LM, MacLaren J, McGrath PJ, Camfield CS, Finley GA. Caregivers' beliefs regarding pain in children with cognitive impairment: Relation between pain sensation and reaction increases with severity of impairment. Clin J Pain 2003;19:335-44.

15. Symons FJ, Shinde SK, Gilles E. Perspectives on pain and intellectual disability. J Intellectual Disabil Res 2008;52:275-86.

16. Breau LM, Burkitt CC. Assessing pain in children with intellectual disabilities. Pain Res Manage 2009;4:116-20.
17. Oberlander TF, Burkitt CC, Symons FJ. Pain in individuals with intellectual disabilities. In: Lynch M, Craig K, Peng P, eds. Clinical Pain Management: A Practical Guide. Oxford: Wiley-Blackwell, 2010.

18. Howard R, Carter B, Curry J, et al. Pain assessment. Paediatr Anaesth 2008;18:14-8

19. Rosenbaum P, Paneth N, Leviton A, et al. A report: The definition and classification of cerebral palsy. Dev Med Child Neurol Suppl 2007;109:8-14. 


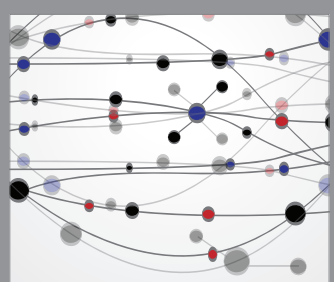

The Scientific World Journal
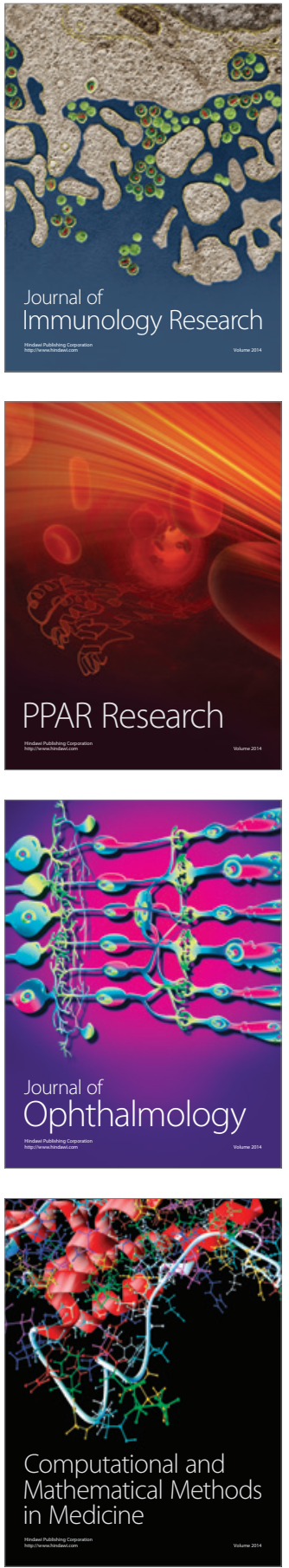

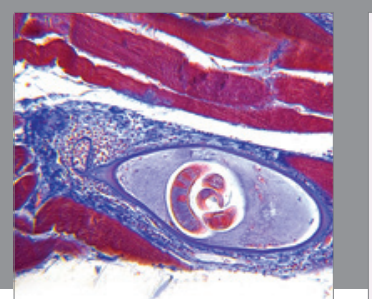

Gastroenterology Research and Practice

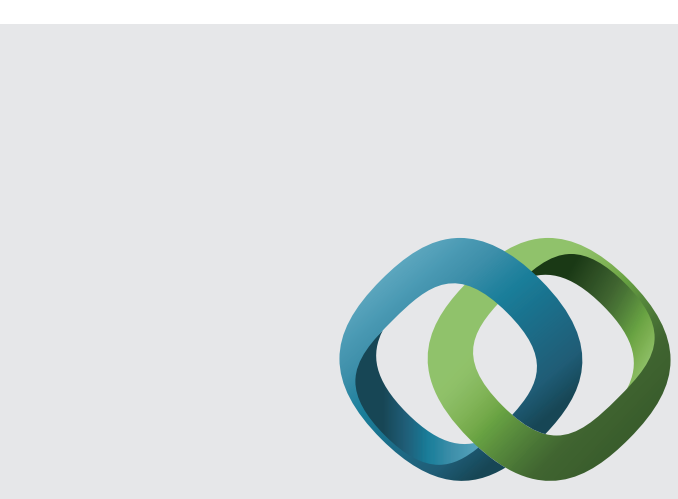

\section{Hindawi}

Submit your manuscripts at

http://www.hindawi.com
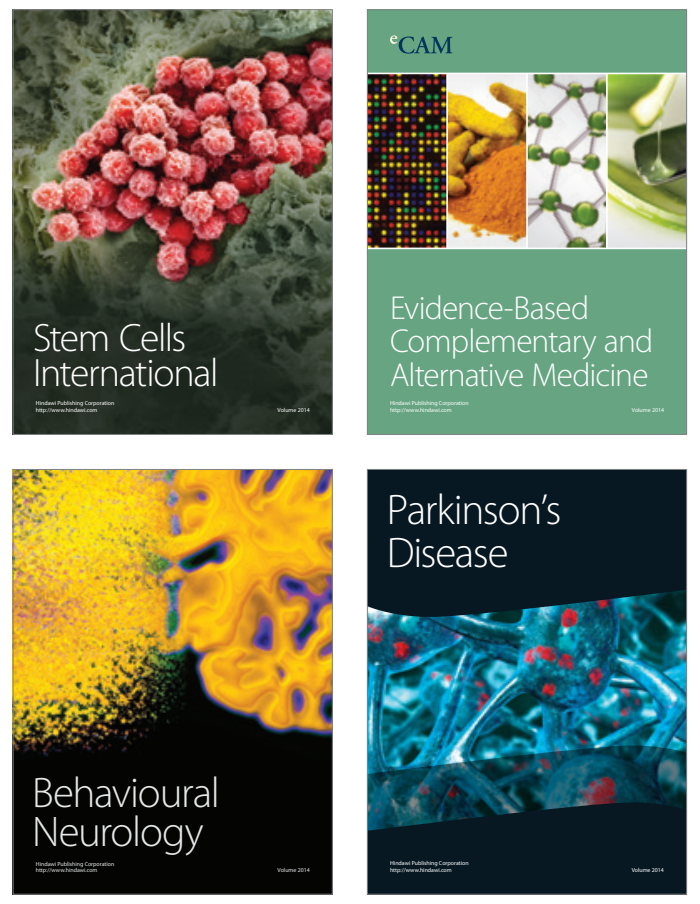
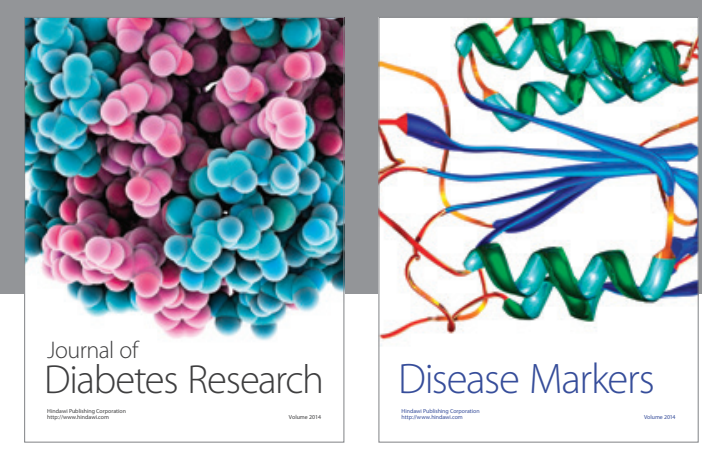

Disease Markers
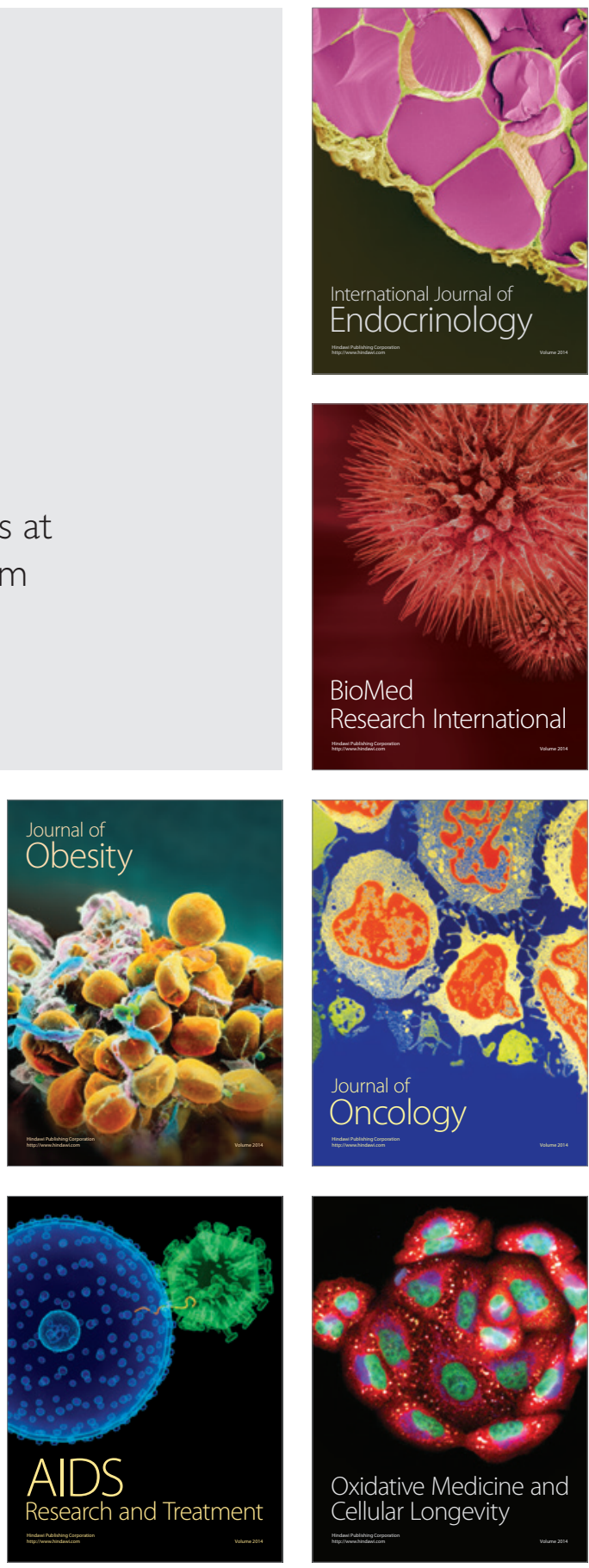